Original Research

\title{
Assessment of Saddle Fit in Racehorses Using Infrared Thermography
}

\author{
Maria Soroko ${ }^{\mathrm{a}, *}$, Przemysław Cwynar ${ }^{\mathrm{b}}$, Kevin Howell ${ }^{\mathrm{c}}$, Kelly Yarnell ${ }^{\mathrm{d}}$, Krzysztof Dudek $^{\mathrm{e}}$, Daniel Zaborski ${ }^{\mathrm{f}}$ \\ a Department of Horse Breeding and Equestrian Studies, Institute of Animal Breeding, Wroclaw University of Environmental and Life Sciences, Wroclaw, Poland \\ ${ }^{\mathrm{b}}$ Department of Environmental Hygiene and Animal Welfare, Wroclaw University of Environmental and Life Sciences, Wroclaw, Poland \\ Microvascular Diagnostics, Institute of Immunity and Transplantation, Royal Free Hospital, London, UK \\ d Nottingham Trent University, School of Animal, Rural and Environmental Sciences, Brackenhurst Campus, Southwell, Nottinghamshire, UK \\ ${ }^{\mathrm{e}}$ Faculty of Mechanical Engineering, Wroclaw University of Technology, Wroclaw, Poland \\ ${ }^{\mathrm{f}}$ Department of Ruminants Science, West Pomeranian University of Technology, Szczecin, Poland
}

\section{A R T I C L E I N F O}

Article history:

Received 17 November 2017

Received in revised form 8 January 2018

Accepted 12 January 2018

Available online xxx

\section{Keywords:}

Infrared thermography

Saddle fit

Racing horse

Load

Rider

\section{A B S T R A C T}

The aim of this study was to assess the influence of horse, saddle, and rider on saddle fit in racehorses by detecting pressure distribution using infrared thermography. In this study, 22 saddles used on 65 racing horses ridden by 21 riders were used. Data from horses including gender, breed, age, training intensity, and level of performance were collected. Type and mass of the saddle were also obtained, along with information about the rider's body mass and riding skills. Thermographic images of the saddle's panels were captured immediately after untacking the horse at each thermographic examination. On each thermographic image of the saddle panels, six regions of interest (ROIs) were marked, with mean temperature calculated within each ROI to indicate pressure distribution. Saddle fit was evaluated for right/left panel pressure, bridging/rocking pressure, and front/back pressure according to horse's: gender, breed, age, training intensity, level of conditioning, rider's skills, and load (saddle plus rider mass). There were statistically significant relationships $(P<.05)$ between left/right asymmetry and age, training, intensity and load. In front/back pressure, there was a statistically significant relationship $(P<.05)$ for load. No statistically significant relationships were observed between bridging/rocking pressure and the rest of the aforementioned variables. The study indicated that load, horse age, and training intensity influence pressure distribution in racing saddles. Therefore, animal age and load have to be considered in saddle fit. Infrared thermography has been confirmed as a useful tool in the evaluation of saddle fit in racing horses.

\section{Introduction}

Back pain is one of the most common clinical problems encountered in performance horses [1]. Back pathologies are mainly associated with soft tissue injuries or spinal stress fractures [2]. It has been reported in many studies that a contributing factor to back pain in horses is a badly fitting saddle [3-5].

An ill-fitting saddle can contribute to pain on palpation, direct and compensatory overt lameness, gait alterations [6,7], and behavioral changes [4]. Therefore, it is important that objective scientific studies be carried out to identify variables that could impact on saddle fit.

Animal welfare/ethical statement: The study was approved by the second Local Ethical Committee of Experimental Procedures on Animals in Wroclaw, Poland (protocol no. 44/2014).

Conflict of interest statement: None of the authors has any financial or personal relationships that could inappropriately influence or bias the content of the manuscript.

* Corresponding author at: Maria Soroko, Department of Horse Breeding and Equestrian Studies, Institute of Animal Breeding, Wroclaw University of Environmental and Life Sciences, Kozuchowska 5A, 51-161 Wroclaw, Poland. Email address: kontakt@eqma.pl (M. Soroko)
Some preliminary studies have used pressure-sensing mats for the objective measurement of saddle fit [8-10]. These devices have been validated for both accuracy and reliability of their force-sensing technology $[1,11,12]$. An alternative method for determining the pressure distribution across the saddle can be obtained through the use of infrared thermography (IRT) on the saddle panels $[13,14]$.

Infrared thermography is a noninvasive imaging method that enables superficial heat emission to be detected, indicating the surface temperature [15]. Potential equine veterinary applications of IRT have been described [16-18], including the study of back injuries. Infrared thermography has been used in detecting disease of the thoracolumbar region, muscular pathologies [19], and spinous process inflammation of the thoracic vertebrae [20].

Application of IRT in the evaluation of saddle fit offers a rapid and easy method which is more practical than other measurement methods available. Infrared thermography examination in saddle fit indicates the temperature distribution, and thus the interaction between the saddle and the surface of the back. In a correctly fitted saddle, pressure distribution should be even on both sides of the spine and back [13]. Locally warmer areas on the back can be detected by IRT with at least 10 times more sensitivity than palpation by the human hand and indicate regions of higher saddle pressure. As a result, 
pressure points can be easily identified and localized. According to Turner et al. [13], the most commonly identified problems are bridging and rocking of the saddle. In the study presented by Arruda et al. [14], IRT proved to be a useful imaging technique to assess saddle fit used on jumpers. However, no research to date has presented quantitative analysis of the observed pressure distribution on saddle panels. The aim of this study was to assess the influence of horse, saddle, and rider on saddle fit in racehorses by detecting pressure distribution using IRT.

\section{Materials and Methods}

\subsection{Data Collection}

Sixty-five clinically healthy racehorses (49 Thoroughbreds and 16 Arabians) of mixed gender (32 mares, 29 stallions, and four geldings), aged between 2 and 6 years were studied, with a total of 22 saddles used. Horses had varying levels of fitness (high, moderate, and low condition) which was determined by the trainer of each stable. Horses were trained for flat racing at Partynice Racecourse (Poland) during the 2016 season. The horses were housed at three different racing stables with varied training intensity (stable A-28 horses, stable B-8 horses, and stable C-19 horses). Horses had similar management regimes but were trained at different intensity levels depending on their trainer, on the same racetrack, in a clockwise direction.

Two types of racing saddle were used during the study: 16 were hard with a tree at the seat and back of the saddle, and six were soft without a tree (stable A-nine saddles, stable B-6 saddles, and stable $\mathrm{C}-$ seven saddles). The mass of the saddles (including stirrups and girth) was between $4 \mathrm{~kg}$ and $6 \mathrm{~kg}$. Twenty-one riders participated in the study. Each stable had their own riders (stable A-nine riders, stable B-six riders, and stable $\mathrm{C}$-six riders), with mean body mass: $59.5 \mathrm{~kg}, \mathrm{SD}=8.2 \mathrm{~kg}, \mathrm{Min}=50.0 \mathrm{~kg}$, and $\mathrm{Max}=80.0 \mathrm{~kg}$. Riders were classified by trainers according to their riding skills: very good, good, and average.

Thermographic measurement of the saddle was conducted on each horse in duplicate ( 2 weeks apart). On both days, horses were tacked up in the same way using a single numnah and underwent training comprising of warm-up (walk and trot) for 10 minutes and then canter at a distance of 2,200 $\mathrm{m}$ for 20 minutes. Horses were ridden in the same way: rising trot and two point seat in canter. After training, they were untacked in the stable and cooled down on an automatic horse walker for approximately 20 minutes. On the second examination day, each horse was ridden by a different rider and was fitted with a different saddle.

\subsection{Infrared Thermography}

Thermographic images were captured using a VarioCAM hr Resolution infrared camera (uncooled microbolometer focal plane array, focal plane sensor array: $640 \times 480$ pixels, spectral range $7.5-14 \mu \mathrm{m}$, accuracy $\pm 1^{\circ} \mathrm{C}$, sensitivity $0.02^{\circ} \mathrm{C}$, InfraTec, Dresden, Germany). The protocol for thermography examination was as previously described by Van Hoogmoed et al. [21] and Soroko et al. [22]. To minimize the effect of environmental factors, thermography was always performed within an enclosed stable (in the horse's box) to avoid sun radiation and air drafts.

Thermographic measurements of the saddle were captured, 2-3 seconds after untacking the horse (Fig. 1).

The distance of the saddle from the camera was fixed for all imaging at $1 \mathrm{~m}$, and the emissivity $(\varepsilon)$ was set to 1 for all readings as per

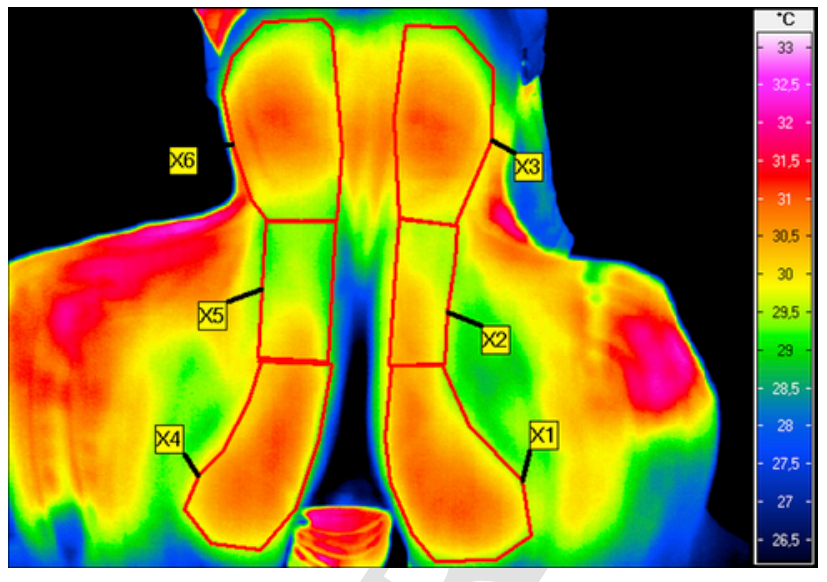

Fig. 1. Example thermographic image of saddle panels taken immediately after untacking the horse, with the six regions of interest (ROIs) indicated: right front of the saddle (X1), right middle of the saddle (X2), right back of the saddle (X3), left front of the saddle (X4), left middle of the saddle (X5), and left back of the saddle (X6).

the protocol of Arruda et al. [14]. All thermographic imaging was performed by the same operator (M.S.).

\subsection{Data Analysis}

On each thermographic image of the saddle panels, six regions of interest (ROIs) were marked as shown in Fig. 1, and the mean temperature within each ROI was defined and calculated as follows:

$\mathrm{X} 1$ = the average temperature in the region ROI1 (right side - front of the saddle)

$\mathrm{X} 2$ = the average temperature in the region ROI2 (right side-middle of the saddle)

$\mathrm{X} 3=$ the average temperature in the region ROI3 (right side- back of the saddle)

$\mathrm{X} 4=$ the average temperature in the region ROI4 (left side- - front of the saddle)

$\mathrm{X} 5=$ the average temperature in the region ROI5 (left side-middle of the saddle)

$\mathrm{X} 6=$ the average temperature in the region ROI6 (left side — back of the saddle)

The mean temperature was calculated using IRBIS 3 Professional software (InfraTec).

\subsection{Statistical Analysis}

Saddle fit was evaluated according to the following:

- Horse's: gender, breed, age, training intensity, and conditioning.

- Rider's skills.

- Type of saddle.

- Loading (saddle mass plus rider's body mass).

To evaluate pressure distribution of saddle, the following indicators of temperature were taken into consideration:

$\mathrm{TI} 1=(\mathrm{X} 1+\mathrm{X} 2+\mathrm{X} 3)-(\mathrm{X} 4+\mathrm{X} 5+\mathrm{X} 6)$-right/left pressure:

- Right-hand pressure: $(\mathrm{X} 1+\mathrm{X} 2+\mathrm{X} 3)-(\mathrm{X} 4+\mathrm{X} 5+\mathrm{X} 6) \geq+0.5^{\circ} \mathrm{C}$; saddle places more pressure in the right panel.

- Even pressure: $-0.5^{\circ} \mathrm{C}<(\mathrm{X} 1+\mathrm{X} 2+\mathrm{X} 3)-(\mathrm{X} 4+\mathrm{X} 5+\mathrm{X} 6)$ $<+0.5^{\circ} \mathrm{C}$; even thermal patterns between right and left panel.

- Left hand pressure: $(\mathrm{X} 1+\mathrm{X} 2+\mathrm{X} 3)-(\mathrm{X} 4+\mathrm{X} 5+\mathrm{X} 6) \leq-0.5^{\circ} \mathrm{C}$, saddle places more pressure in the left panel. 
$\mathrm{TI} 2=(\mathrm{X} 2+\mathrm{X} 5) / 2-(\mathrm{X} 1+\mathrm{X} 4+\mathrm{X} 3+\mathrm{X} 6) / 4$ - bridging/rocking pressure:

- Bridging pressure: $(\mathrm{X} 2+\mathrm{X} 5) / 2-(\mathrm{X} 1+\mathrm{X} 4+\mathrm{X} 3+\mathrm{X} 6) / 4<-0.5^{\circ} \mathrm{C}$, both panels place pressure at the front and back.

- Even pressure: $-0.5^{\circ} \mathrm{C}<(\mathrm{X} 2+\mathrm{X} 5) / 2-(\mathrm{X} 1+\mathrm{X} 4+\mathrm{X} 3+\mathrm{X} 6) / 4<$ $0.5^{\circ} \mathrm{C}$; even thermal patterns between right and left panel.

- Rocking pressure: $(\mathrm{X} 2+\mathrm{X} 5) / 2-(\mathrm{X} 1+\mathrm{X} 4+\mathrm{X} 3+\mathrm{X} 6) / 4>0.5^{\circ} \mathrm{C}$, both panels place pressure at the cantle.

\subsection{TI3—Front/Back Pressure}

- Front saddle pressure: $(\mathrm{X} 1+\mathrm{X} 4) \geq(\mathrm{X} 2+\mathrm{X} 5) \geq(\mathrm{X} 3+\mathrm{X} 6)$; both panels place pressure at the front.

- Even pressure; even thermal patterns between right and left panel.

- Back saddle pressure: $(\mathrm{X} 1+\mathrm{X} 4) \leq(\mathrm{X} 2+\mathrm{X} 5) \leq(\mathrm{X} 3+\mathrm{X} 6)$; both panels place pressure at the back.

The hypothesis regarding the dependence of the saddle panel temperature distribution on the parameters related to the saddle type, horse level of performance and skills of the rider, and the mass of the rider and saddle was verified using Pearson's chi-squared test. Due to multiple comparisons and the increased likelihood of a Type- 1 error, the Bonferroni-Holm correction was used to increase the significance level of the test. Calculations were made using STATISTICA, version 12 (StatSoft, Inc., Tulsa, OK).

\section{Results}

The relationship between surface temperature of the saddle panels and the investigated variables (gender, breed, age, training intensity, level of conditioning, rider's skills, type of saddle, and loading) is presented in Tables 1-3.

There was a statistically significant association $(P<.05)$ between left/right pressure and the variables of age, training intensity, and load (Table 1). No significant associations were found for the remaining variables. No statistically significant relationships were observed for bridging/rocking pressure in any of the variables tested (Table 2).

The analysis of the effect of factors associated with horse, rider, and saddle on the front/back pressure in temperature distribution indicated that there was a statistically significant relationship $(P<.05)$ present between the load and the front/back pressure (Table 3$)$.

\section{Discussion}

The study indicated that load, horse age, and training intensity influence pressure distribution in racing saddles. The research also confirmed IRT to be a useful tool in the evaluation of saddle fit in racing horses. The research findings on the use of IRT to assess pressure distribution of saddles are broadly in agreement with those of Arruda et al. [14] and Turner et al. [13]. Even surface temperature distribution (indicating even distribution of pressure) between the panels of a saddle is one of the most important aspects of the IRT saddle fit evaluation [13]. Arruda et al. [14] assessed 62 jumping saddles on 129 jumping horses using IRT. Even pressure distribution between saddle panels and the horses' back was observed on $52.2 \%$ of saddles (panel interaction $75 \%-100 \%$ ). Saddles with a panel interaction of up to $75 \%$, $50 \%$, and $25 \%$ were less frequent $(30.2 \%, 13.2 \%$, and $5.4 \%$, respectively). Asymmetry between the saddle panels was evident in $62.8 \%$ of cases. According to the authors, the high percentage of asymmetric saddles can be associated with incorrect adjustment of the saddles to sport horses.
Table 1

Surface temperature distribution on the saddle panels within each variable tested, reported as a proportion of right pressure placement, left pressure placement, or even pressure placement.

\begin{tabular}{|c|c|c|c|c|c|c|c|}
\hline \multirow[t]{3}{*}{ Variable } & \multicolumn{6}{|c|}{$\begin{array}{l}\text { The Temperature Distribution of the Saddle's } \\
\text { Panels }\end{array}$} & $\begin{array}{l}\text { Chi-Square } \\
\text { Test }(P)\end{array}$ \\
\hline & \multicolumn{2}{|c|}{$\begin{array}{l}\text { Right } \\
\text { Pressure } \\
\mathrm{N}=27\end{array}$} & \multicolumn{2}{|c|}{$\begin{array}{l}\text { Even Pressure } \\
\mathrm{N}=55\end{array}$} & \multicolumn{2}{|c|}{$\begin{array}{l}\text { Left Pressure } \\
\mathrm{N}=48\end{array}$} & \\
\hline & $\mathrm{n}$ & $\%$ & $\mathrm{n}$ & $\%$ & $\mathrm{n}$ & $\%$ & \\
\hline 1. Gender & & & & & & & .612 \\
\hline Mare & 15 & 55.6 & 26 & 47.3 & 23 & 47.9 & \\
\hline Gelding & 3 & 11.1 & 3 & 5.5 & 2 & 4.2 & \\
\hline Stallion & 9 & 33.3 & 26 & 47.3 & 23 & 47.9 & \\
\hline 2. Breed & & & & & & & .874 \\
\hline Arabian & 6 & 22.2 & 13 & 23.6 & 13 & 27.1 & \\
\hline Thoroughbred & 21 & 77.8 & 42 & 76.4 & 35 & 72.9 & \\
\hline 3. Age (y) & & & & & & & .024 \\
\hline 2 and 3 & 16 & 59.3 & 50 & 90.9 & 38 & 79.2 & \\
\hline 4,5 , and 6 & 11 & 40.7 & 5 & 9.1 & 10 & 20.8 & \\
\hline 4. Training intensity & & & & & & & .024 \\
\hline Stable A & 6 & 22.2 & 34 & 61.8 & 16 & 33.3 & \\
\hline Stable B & 9 & 33.3 & 13 & 23.6 & 16 & 33.3 & \\
\hline Stable C & 12 & 44.4 & 8 & 14.5 & 16 & 33.3 & \\
\hline $\begin{array}{l}\text { 5. Level of } \\
\text { conditioning }\end{array}$ & & & & & & & .308 \\
\hline High condition & 6 & 22.2 & 11 & 20 & 2 & 4.2 & \\
\hline Moderate condition & 21 & 77.8 & 44 & 80 & 44 & 91.7 & \\
\hline Low condition & 0 & 0 & 0 & 0 & 2 & 4.2 & \\
\hline 6. Skills rider & & & & & & & .375 \\
\hline Very good & 15 & 55.6 & 21 & 38.2 & 27 & 56.3 & \\
\hline Average & 10 & 37 & 30 & 54.5 & 18 & 37.5 & \\
\hline Basic & 2 & 7.4 & 4 & 7.3 & 3 & 6.3 & \\
\hline 7. Type saddle & & & & & & & .092 \\
\hline Soft & 9 & 33.3 & 28 & 50.9 & 11 & 22.9 & \\
\hline Hard & 18 & 66.7 & 27 & 49.1 & 37 & 77.1 & \\
\hline 8. Load (kg) & & & & & & & .001 \\
\hline $45-50$ & 8 & 29.6 & 24 & 43.6 & 17 & 35.4 & \\
\hline $51-55$ & 6 & 22.2 & 20 & 36.4 & 14 & 29.2 & \\
\hline $56-60$ & 0 & 0 & 4 & 7.3 & 6 & 12.5 & \\
\hline $61-65$ & 4 & 14.8 & 3 & 5.5 & 1 & 2.1 & \\
\hline $66-70$ & 0 & 0 & 3 & 5.5 & 8 & 16.7 & \\
\hline $71-75$ & 6 & 22.2 & 1 & 1.8 & 1 & 2.1 & \\
\hline $76-80$ & 3 & 11.1 & 0 & 0 & 1 & 2.1 & \\
\hline
\end{tabular}

Both the saddle and rider place a load on the horse's back during riding [23]. In the present study, we found that differing loads influenced saddle fit in both right and left pressure distribution and front and back pressure distribution when assessed using IRT. Loads between $45-50 \mathrm{~kg}$ and $51-55 \mathrm{~kg}$ presented the highest incidences of even pressure distribution ( $43.6 \%$ and $36.4 \%$, respectively) when considering left-right pressure asymmetry. Similarly, in the case of front back asymmetry, loads between $45-50 \mathrm{~kg}$ and $51-55 \mathrm{~kg}$ presented the highest even pressure distribution in $43.4 \%$ and $45.3 \%$ cases, respectively.

Interestingly, when examining the right and left pressure of the saddles' panels, we found increased pressure points on the left side compared with the right side in load between $45-50 \mathrm{~kg}$ and $51-55 \mathrm{~kg}$. Horses in our study were trained in a clockwise direction (right side) around the racetrack, which could have had an effect on the rider's position and balance.

It was previously confirmed that contact between the saddle and the horse's back is influenced by rider position and technique [12,24] and the rider's level of training [25]. However, in the present study, there was no association between the rider's skills and saddle fit. Similar results were presented by Arruda et al. [14], where no association was found between the asymmetry of the saddle and the rider's experience level $(P=.46)$. However, previous studies have indicated an influence of rider's ability on saddle fit $[12,24]$. When the horse is 
Table 2

Surface temperature distribution on the saddle panels within each variable tested, reported as a proportion of bridge placement, rocking placement, or even pressure placement.

\begin{tabular}{|c|c|c|c|c|c|c|c|}
\hline \multirow[t]{3}{*}{ Variable } & \multicolumn{6}{|c|}{$\begin{array}{l}\text { The Temperature Distribution of the Saddle's } \\
\text { Panels }\end{array}$} & \multirow[t]{3}{*}{$\begin{array}{l}\text { Chi-Squar } \\
\text { Test }(P)\end{array}$} \\
\hline & \multicolumn{2}{|c|}{$\begin{array}{l}\text { Bridge } \\
\mathrm{N}=7\end{array}$} & \multicolumn{2}{|c|}{$\begin{array}{l}\text { Even } \\
\text { Pressure } \\
\mathrm{N}=96\end{array}$} & \multicolumn{2}{|c|}{$\begin{array}{l}\text { Rocking } \\
\mathrm{N}=27\end{array}$} & \\
\hline & $\mathrm{n}$ & $\%$ & $\mathrm{n}$ & $\%$ & $\mathrm{n}$ & $\%$ & \\
\hline 1. Gender & & & & & & & .397 \\
\hline Mare & 1 & 14.3 & 50 & 52.1 & 13 & 48.1 & \\
\hline Gelding & 1 & 14.3 & 5 & 5.2 & 2 & 7.4 & \\
\hline Stallion & 5 & 71.4 & 41 & 42.7 & 12 & 44.4 & \\
\hline 2. Breed & & & & & & & .177 \\
\hline Arabian & 0 & 0 & 27 & 28.1 & 5 & 18.5 & \\
\hline Thoroughbred & 7 & 100 & 69 & 71.9 & 22 & 81.5 & \\
\hline 3. Age (y) & & & & & & & .409 \\
\hline 2 & 3 & 42.9 & 30 & 31.3 & 11 & 40.7 & \\
\hline 3 & 4 & 57.1 & 48 & 50 & 8 & 29.6 & \\
\hline 4 & 0 & 0 & 4 & 4.2 & 4 & 14.8 & \\
\hline 5 & 0 & 0 & 8 & 8.3 & 2 & 7.4 & \\
\hline 6 & 0 & 0 & 6 & 6.3 & 2 & 7.4 & \\
\hline 4. Training intensity & & & & & & & .180 \\
\hline Stable A & 4 & 57.1 & 40 & 41.7 & 12 & 44.4 & \\
\hline Stable B & 0 & 0 & 33 & 34.4 & 5 & 18.5 & \\
\hline Stable C & 3 & 42.9 & 23 & 24 & 10 & 37 & \\
\hline $\begin{array}{l}\text { 5. Level of } \\
\text { conditioning }\end{array}$ & & & & & & & .254 \\
\hline High condition & 3 & 42.9 & 16 & 16.7 & 0 & 0 & \\
\hline Moderate condition & 4 & 57.1 & 78 & 81.3 & 27 & 100 & \\
\hline Low condition & 0 & 0 & 2 & 2.1 & 0 & 0 & \\
\hline 6. Skills rider & & & & & & & .081 \\
\hline Very good & 4 & 57.1 & 49 & 51 & 10 & 37 & \\
\hline Average & 1 & 14.3 & 42 & 43.8 & 15 & 55.6 & \\
\hline Basic & 2 & 28.6 & 5 & 5.2 & 2 & 7.4 & \\
\hline 7. Type saddle & & & & & & & .170 \\
\hline Soft & 6 & 85.7 & 33 & 34.4 & 9 & 33.3 & \\
\hline Hard & 1 & 14.3 & 63 & 65.6 & 18 & 66.7 & \\
\hline 8. Load (kg) & & & & & & & .221 \\
\hline $45-50$ & 1 & 14.3 & 37 & 38.5 & 11 & 40.7 & \\
\hline $51-55$ & 5 & 71.4 & 23 & 24 & 12 & 44.4 & \\
\hline $56-60$ & 0 & 0 & 9 & 9.4 & 1 & 3.7 & \\
\hline $61-65$ & 0 & 0 & 8 & 8.3 & 0 & 0 & \\
\hline $66-70$ & 0 & 0 & 9 & 9.4 & 2 & 7.4 & \\
\hline $71-75$ & 1 & 14.3 & 6 & 6.3 & 1 & 3.7 & \\
\hline $76-80$ & 0 & 0 & 4 & 4.2 & 0 & 0 & \\
\hline
\end{tabular}

ridden, it has to endure not only the static body mass of the rider but also the dynamic load when moving [23]. Studies investigating pressure exerted through the saddle have indicated different pressure distribution in walk, trot, and canter [26]. According to Peham et al. [27], the highest load (expressed in Newtons [N]) on the horse's back is encountered during a sitting trot $(2112 \mathrm{~N})$, followed by a rising trot $(2056 \mathrm{~N})$ and the two point seat jumping position (1688 N). These findings could also have had an influence on the results of the previous studies discussed. Interestingly, in earlier studies, Peham et al. [28] demonstrated the beneficial effect of a rider on the motion pattern variability of the horse's gait. In the same study, it was indicated that motion variability was significantly lower with a correctly fitted saddle than an incorrectly fitted saddle. As suggested by Harman $[3,10]$, an incorrectly fitted saddle has an influence on the horse's motion and the rider's seat.

The type of saddle must also be considered when determining correct saddle fit. Saddles that have a tree are designed to distribute the rider's body mass over a large area, with a uniform distribution of force. In contrast, studies on treeless racing saddles in combination with a saddle pad indicate the lack of an even distribution of the rider's body mass [29]. Similar results were presented by Belock et al.
Table 3

Surface temperature distribution on the saddle panels within each variable tested, reported as a proportion of front placement, back placement, or even pressure placement.

\begin{tabular}{|c|c|c|c|c|c|c|c|}
\hline \multirow[t]{3}{*}{ Variable } & \multicolumn{6}{|c|}{$\begin{array}{l}\text { The Temperature Distribution of the } \\
\text { Saddle's Panels }\end{array}$} & \multirow[t]{3}{*}{$\begin{array}{l}\text { Chi-Square } \\
\text { Test }(P)\end{array}$} \\
\hline & \multicolumn{2}{|c|}{$\begin{array}{l}\text { Front } \\
\mathrm{N}=66\end{array}$} & \multicolumn{2}{|c|}{$\begin{array}{l}\text { Even Pressure } \\
\mathrm{N}=53\end{array}$} & \multicolumn{2}{|c|}{$\begin{array}{l}\text { Back } \\
\mathrm{N}=11\end{array}$} & \\
\hline & $\mathrm{n}$ & $\%$ & $\mathrm{n}$ & $\%$ & $\mathrm{n}$ & $\%$ & \\
\hline 1. Gender & & & & & & & .062 \\
\hline Mare & 42 & 63.6 & 18 & 34 & 4 & 36.4 & \\
\hline Gelding & 3 & 4.5 & 3 & 5.7 & 2 & 18.2 & \\
\hline Stallion & 21 & 31.8 & 32 & 60.4 & 5 & 45.5 & \\
\hline 2. Breed & & & & & & & .320 \\
\hline Arabian & 11 & 16.7 & 19 & 35.8 & 2 & 18.2 & \\
\hline Thoroughbred & 55 & 83.3 & 34 & 64.2 & 9 & 81.8 & \\
\hline 3. Age (y) & & & & & & & .171 \\
\hline 2 & 21 & 31.8 & 19 & 35.8 & 4 & 36.4 & \\
\hline 3 & 26 & 39.4 & 29 & 54.7 & 5 & 45.5 & \\
\hline 4 & 5 & 7.6 & 3 & 5.7 & 0 & 0.0 & \\
\hline 5 & 7 & 10.6 & 1 & 1.9 & 2 & 18.2 & \\
\hline 6 & 7 & 10.6 & 1 & 1.9 & 0 & 0 & \\
\hline 4. Training intensity & & & & & & & .079 \\
\hline Stable A & 30 & 45.5 & 23 & 43.4 & 3 & 27.3 & \\
\hline Stable B & 19 & 28.8 & 18 & 34 & 1 & 9.1 & \\
\hline Stable C & 17 & 25.8 & 12 & 22.6 & 7 & 63.6 & \\
\hline $\begin{array}{l}\text { 5. Level of } \\
\text { conditioning }\end{array}$ & & & & & & & .266 \\
\hline High condition & 9 & 13.6 & 8 & 15.1 & 2 & 18.2 & \\
\hline Moderate condition & 56 & 84.8 & 45 & 84.9 & 8 & 72.7 & \\
\hline Low condition & 1 & 1.5 & 0 & 0 & 1 & 9.1 & \\
\hline 6. Rider skills & & & & & & & .062 \\
\hline Very good & 36 & 54.5 & 20 & 37.7 & 7 & 63.6 & \\
\hline Average & 30 & 45.5 & 26 & 49.1 & 2 & 18.2 & \\
\hline Basic & 0 & 0 & 7 & 13.2 & 2 & 18.2 & \\
\hline 7. Kind of saddle & & & & & & & .302 \\
\hline Soft & 20 & 30.3 & 26 & 49.1 & 2 & 18.2 & \\
\hline Hard & 46 & 69.7 & 27 & 50.9 & 9 & 81.8 & \\
\hline 8. Load (kg) & & & & & & & .047 \\
\hline $45-50$ & 22 & 33.3 & 23 & 43.4 & 4 & 36.4 & \\
\hline $51-55$ & 13 & 19.7 & 24 & 45.3 & 3 & 27.3 & \\
\hline $56-60$ & 10 & 15.2 & 0 & 0 & 0 & 0 & \\
\hline $61-65$ & 6 & 9.1 & 1 & 1.9 & 1 & 9.1 & \\
\hline $66-70$ & 9 & 13.6 & 1 & 1.9 & 1 & 9.1 & \\
\hline $71-75$ & 4 & 6.1 & 2 & 3.8 & 2 & 18.2 & \\
\hline $76-80$ & 2 & 3 & 2 & 3.8 & 0 & 0 & \\
\hline
\end{tabular}

[30] on dressage treeless saddles, which had a smaller weight-bearing area, focal concentration of pressure under the rider's seat bones, and higher maximal pressures compared with a tree saddle at sitting trot. The present study included two types of saddles: with and without tree. However, we found no influence of type of the saddle on saddle fit.

Saddle fit must also consider the conformation and condition of the horse. Arruda et al. [14] found a correlation between panel asymmetry and horse's body score $\left(r^{2}=-0.24 ; P=.005\right)$. Body condition is influenced by several different factors, including training, diet, and age. In our study, we found more even pressure distribution across the saddle in young horses (2-3 years old) than older horses. This could be attributed to different body conditions and conformation between the two groups of horses. Horses aged $2-3$ years potentially have different musculature at the beginning of their training when compared with older horses (4-6 years), which are in regular training. The loss of body condition and muscle atrophy can lead to an incorrectly fitting saddle [13]. Therefore, conformation differences between horses trained with the same saddles could have a detrimental impact [31,32]. As the shape of the horse's back is continually changing, regular saddle checks should be made.

There were some limitations to the present study. The studied racing saddles were used by different riders on different horses. In stable 
A, nine saddles were used on 27 horses, in stable B, 6 saddles were used on 18 horses, and in stable C, seven saddles were used on 19 horses. The number of saddles was lower than the number of horses in each stable, and there was a need to use one saddle on many horses. Saddles used frequently by different riders on different horses could increase the frequency of asymmetry between pressure distributions during this study. In a similar study by Arruda et al. [14], saddles were used on $4.6 \pm 3.7$ horses by $2.1 \pm 1.0$ different riders. Therefore, the large number of horses ridden with different saddles indicates that horses cannot have a well-fitted saddle.

This work will contribute to easily performed and efficient evaluation of saddle fit using IRT. However, more research is required on different saddles, to confirm these initial findings.

\section{Conclusions}

Key findings were that load, training intensity, and horse age can influence pressure distribution. It is therefore important that the age of the horse and expected load be considered when determining correct saddle fit. In the present study, IRT as a noninvasive tool was found to be useful in the evaluation of saddle fit in racing horses by measuring surface temperature as an indirect assessment of pressure distribution. When applying IRT, consideration must be made during interpretation of findings into external factors that can influence the final results.

\section{Acknowledgments}

The authors like to thank the trainers and riders from Wroclaw Racetrack-Wroclawski Tor Wyscigow Konnych Partynice for their help with the study.

\section{References}

[1] L.B. Jeffcott, M.A. Holmes, H.G. Townsend, Validity of saddle pressure measurements using force sensing array technology preliminary studies, Vet $\mathrm{J}$ 158 (1999) 113-139.

[2] M.J. Head, Back pathology in racehorses, in: F.M.D. Henson (Ed.), Equine back pathology, Wiley-Blackwell, United Kingdom, 2009, pp. 213-222.

[3] J.C. Harman, Practical saddle fitting, Equine Ath 8 (1995) 6-19.

[4] J.C. Harman, Tack and saddle fit, in: S. Turner, K.K. Haussler (Eds.), Veterinary clinics of North American equine practice: back problems, Philadelphia, London, Toronto, Saunders Company, Montreal, Sydney, Tokyo, 1999, pp. 247-261.

[5] P. De Cocq, P.R. Van Weeren, W. Back, Effects of girth, saddle and weight on movements of the horse, Equine Vet J 36 (2004) 758-763.

[6] L.B. Jeffcott, Historical perspective and clinical indications, Vet Clin North Am Equine Pract 15 (1999) 1-12.

[7] J.M. Denoix, Spinal biomechanics and functional anatomy, Vet Clin North Am Equine Pract 15 (1999) 27-60.

[8] J.C. Harman, Practical use of a computerised saddle pressure measuring device to determine the effects of saddle pads on the horse's back, Equine Vet Sci 14 (1994) 606-611.

[9] J.G. Pullin, M.A. Collier, C.M. Durham, R.K. Miller, Use of force sensing array technology in the development of a new equine saddle pad: static and dynamic evaluations and technical considerations, J Equine Vet Sci 16 (1996) 207-216.
[10] J.C. Harman, Measurement of the pressures exerted by saddles on the horses back using an computerized pressure measuring device, Pferdeheilkunde 13 (1997) 129-134.

[11] D. Werner, S. Nyikos, A. Kalpen, M. Geuder, C. Haas, H.D. Vontobel, J.A Auer, B.v. Rechenberg, Druckmessungen unter dem Sattel: eine Studie mit einem elektronischen Sattel-Messsystem (Novel GmbH), Pferdeheilkunde 18 (2002) 125-140.

[12] P. De Cocq, H.M. Clayton, K. Terada, M. Muller, J.L. van Leeuwen, Usability of normal force distribution measurements to evaluate asymmetrical loading of the back of the horse and different rider positions on a standing horse, Vet J 181 (2009) 266-273.

[13] T.A. Turner, J.K. Waldsmith, J.H. Wilson, How to assess saddle fit in horses, Proc Am Assoc Equine Pract 50 (2004) 196-201.

[14] T.Z. Arruda, K.E. Brass, F.D. De La Corte, Thermographic assessment of saddles used on jumping horses, J Equine Vet Sci 31 (2011) 625-629.

[15] K. Cena, Radiative heat loss from animal and man, in: J.L. Monteih, L.E. Mount (Eds.), Heat loss from animals and man, Butterworths, London, Great Britain, 1974, pp. $34-57$

[16] T.A. Turner, Diagnostic thermography, Vet Clin North Am Equine Pract 17 (2001) 95-113.

[17] M. Soroko, R. Henklewski, H. Filipowski, E. Jodkowska, The effectiveness of thermographic analysis in equine orthopaedics, J Equine Vet Sci 33 (2013) $760-762$.

[18] M. Soroko, K. Howell, Infrared thermography: current applications in equine medicine, J Equine Vet Sci 60 (2018) 90-96.e2.

[19] D.G. Von Schweinitz, Thermographic diagnosis in equine back pain, Vet Clin North Am Equine Pract 15 (1999) 161-177.

[20] , TA. Turner, Alternate methods of soft tissue imaging, Dubai Int Equine Symp 1996, 165-176.

[21] L.M. Van Hoogmoed, J.R. Snyder, A.K. Allen, J.D. Waldsmith, Use of infrared thermography to detect performance - enhancing techniques in horses, Equine Vet Edu 12 (2000) 102-107.

[22] M. Soroko, K. Dudek, K. Howell, E. Jodkowska, R. Henklewski, Thermographic evaluation of racehorse performance, J Equine Vet Sci 34 (2014) 1076-1083.

[23] H.M. Clayton, J.L. Lanovaz, H.C. Schamhardt, R. van Wessum, The effects of a rider's mass on ground reaction forces and fetlock kinematics at the trot, Equine Vet J Suppl 30 (1999) 218-221.

[24] L.B. Jeffcott, K.K. Haussler, Back and pelvis, in: K.W. Hinchcliff, A.J. Kaneps, R.J. Geor (Eds.), Equine medicine and surgery, Saunders, Edinburgh, Scotland, 2005, pp. 433-474.

[25] C. Peham, A. Frey, T. Licka, M. Scheidl, Evaluation of the EMG activity of the long back muscle during induced back movements at stance, Equine Vet J Suppl 33 (2001) 165-168.

[26] B. Fruehwirth, C. Peham, M. Scheidl, H. Schobesberger, Evaluation of pressure distribution under an English saddle at walk, trot and canter, Equine Vet J 36 (2004) 754-757.

[27] C. Peham, A.B. Kotschwar, B. Borkenhagen, S. Kuhnke, J. Molsner, A. Baltacis, A comparison of forces acting on the horse's back and the stability of the rider's seat in different positions at the trot, Vet J 184 (2010) 56-59.

[28] C. Peham, T. Licka, H. Schobesberger, E. Meschan, Influence of the rider on the variability of the equine gait, Hum Mov Sci 23 (2004) 663-671.

[29] S.N. Latif, K. von Peinen, T. Wiestner, C. Bitschnau, B. Renk, M.A. Weishaupt, Saddle pressure patterns of three different training saddles (normal tree, flexible tree, treeless) in Thoroughbred racehorses at trot and gallop, Equine Vet J 42 (2010) 630-636.

[30] B. Belock, L.J. Kaiser, M. Lavagnino, H.M. Clayton, Comparison of pressure distribution under a conventional saddle and a treeless saddle at sitting trot, Vet J 193 (2012) 87-91.

[31] JC. Harman, Alternative medicine in equine practice: part II, Proceedings of the North Am Vet Conference 2005 [Internet], http://www.ivis.org/proceedings/navc/ 2005/LA/083.pdf?LA=1. Accessed November 10, 2017.

[32] A.B. Kotschwar, A. Baltacis, C. Peham, The influence of different saddle pads on force and pressure changes beneath saddles with excessively wide trees, Vet J 184 (2010) 322-325. 